\title{
Study and application of wellbore trajectory optimization for dense cluster wells
}

\author{
Wang-Guona ${ }^{1}{ }^{*}$, and Zhang-Wei ${ }^{2}$ \\ ${ }^{1}$ Dagang Oilfield Petroleum Engineering Research Institute, Tianjin 300280 China \\ ${ }^{2}$ he fifth oil production plant of Dagang Oilfield, Tianjin 300280 China
}

\begin{abstract}
In the middle and late stage of oilfield exploration and development, the difficulties such as land acquisition on the surface, high density of underground well pattern and high development cost are serious. Dense cluster Wells are mainly way to development mode transformation and quality and efficiency improvement. Combined with the practice of dense cluster well in Dagang Oilfield, the paper detailed analyzes the difficulties faced by the design of dense cluster well drilling engineering, which including well pattern arrangement, wellbore trajectory optimization, wells anti-collision, all of those are beneficial to realize benefit drilling development. The applications show that this technology has a significant effect on improving wellsite utilization rate, shortening drilling cycle and reducing drilling cost in Dagang oilfield, and has a very important reference and popularization significance in similar oilfield development.
\end{abstract}

\section{Preface}

Dagang Oilfield is mainly a complex fault-block reservoir. After 56 years of water injection development and multiple rounds of development adjustment, it has a high degree of underground development and a high density of well pattern. Moreover, the surface environment is close to red line areas such as cities, wetlands and coastal tidal flats, and there is a shortage of land on surface for production construction. Dense cluster Wells are mainly mode of the new development. According to the practical experience of Dagang oilfield, the optimization design and research of drilling engineering of dense cluster Wells are carried out in order to ensure the quality and efficiency of exploitation. The paper studied wellbore trajectory optimization, wells anti-collision, and optimization of the operation parameters through the comprehensive of geological demands, difficulty of engineering, engineering technology and economic costs. In conclusion, there is a good application prospect of the technology of high efficiency drilling optimization in large-scale well factory, and it has very important reference and promotion significance in development of similar oilfields.

\section{The difficulty of drilling engineering of dense cluster well}

\subsection{The anti-collision relation rebetween design wells and completion wells is prominent}

The oilfield in the mid-to-late stage of development faces the problems of high development degree, intricate underground targets and high density of completion drilling network. The typical old area of Dagang oilfield has a well pattern density of $44 / \mathrm{km}^{2}$, and the designed anti-collision rate of wells is more than $90 \%$. Moreover, most completed adjacent Wells have been drilled for long time, and the reliability of well data is low. The effective development mode need to improve the utilization rate of well site and control more recoverable reserves, so it presents the characteristics of large well cluster and threedimensional; At the same time the designing Wells number and horizontal Wells with large displacement is more and more, and the targets is scattered, so the anti-collisions between designed Wells is prominent.

For example, the Gangxi No. 2 cluster well platform realized the implementation of 56 designed Wells in the standard well site with an area of $0.4 \mathrm{~km}^{2}$, the well type includs horizontalWells and long-displacement Wells, it also had relationship with more than 200 well-drilled adjacent Wells, it is difficult to optimize wellbore trajectory and design anti-collision.

\subsection{It is difficult to optimize the wellbore trajectory because of the high proportion of $\mathbf{3 d}$ Wells and long-displacement Wells}

Due to the high degree of urbanization, numerous of nature reserves and ecological agriculture reserves in Dagang oilfield, the construction land space of the oilfield production capacity is seriously insufficient, and it is difficult to acquire land at the well site, all of those resulting in diverse wellhead arrangement forms, large deviation distance of the designed well, insufficient displacement in front of the target and other problems, which increase the difficulty of optimizing the wellbore

*E-mail: wanggna@petrochina.com.cn. 
trajectory. For example, during the development of shale oil, the offset is as long as $867 \mathrm{~m}$ and the longest horizontal section is $1500 \mathrm{~m}$. In the process of wellbore trajectory optimization, it is necessary to consider how to reasonable eliminate Offset elimination, satisfy meet the weight on bit transfer, and reduce friction torque.

\subsection{The pressure of drilling engineering optimization design increases sharply because of the requirements of safety, environmental protection, quality and efficiency}

Due to the "two black swans" of COVID-19 and plunging oil prices, it is necessary to consider how to improve the quality and efficiency of drilling engineering. Considered the condition of ensuring design quality, safety and reasonable optimization of wellbore trajectory is needed to reduce construction difficulty, decrease the complexity underground, and cut down the drilling footage, so as to improve the quality and efficiency of drilling engineering design.

\section{The key technology of the drilling engineering of dense cluster well}

\subsection{Study on optimal well net deployment}

During the deployment process of dense cluster Wells, we comprehensively analyzed the feasibility of construction, engineering technology and construction cost in the later stage to ensure the implementation of the cluster Wells benefit optimization which including rational number and type of platform well. Taking Gangxi No.1 platform as an example, the wellsite has 30 original deployment grooves, with 40 deployed geological targets and $5 \mathrm{~m}$ wellhead spacing. According to the analysis and study, it is analyzed that some Wells have problems such as shallow kick off point, large build angle rate, and high well inclination Angle. Combined with the formation characteristics, the dogleg of the second stage was raised to $3.5 \mathrm{deg} / 30 \mathrm{~m}$, and the well angel was still up to $62.78 \mathrm{deg}$. Some deployed Wells were cancelled considering Minghua and Guantao formation in this area is loose and easy to sand-producing and the high comprehensive costs of logging and logging in the later period considering the high comprehensive cost such as late logging and logging caused by large well angel, it is not recommended to implement the well. At the same time, In order to achieve a well targets multiobjective, the prioritization including a directional well, high angle well, big displacement well, horizontal well and multi-objective model borewellbore trajectory optimization is established, and The target orbit design model of complex multi-target well is formed, so as to realize the efficient between unrelated target orbit design, and ensure the well track in the most favorable oil-bearing area through the, in order to realize the economic benefits of development well. The well type is optimized by combining the characteristics of geological reservoir. Xi914-3 and Xi8-14-2 were optimized to xi8-14-2H (Figure 1), which achieved a well multi-objectives. The final overall plan was optimized from 28 Wells to

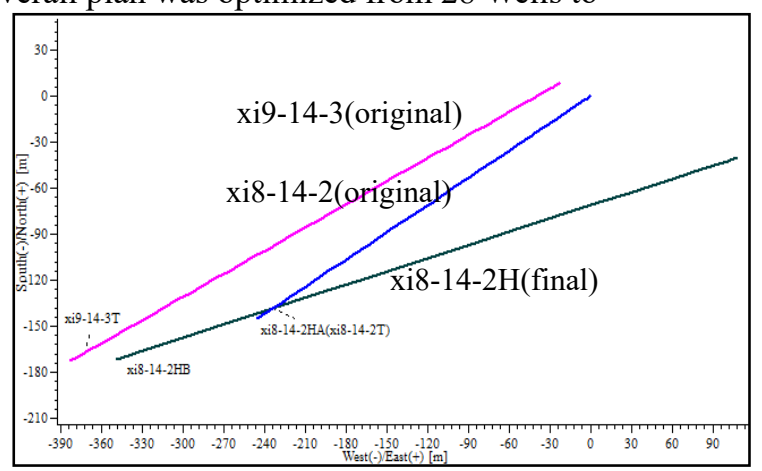

Figure 1 Optimization of multi-target well type in Gangxi No.1 wellplatform

26 , with the concentrated using No. 1-26 grooves, and the wellhead spacing between Wells is optimized to $6 \mathrm{~m}$. The grooves are saved and leaving a good space for the continuous development of cluster wellsites. At the same time, it is conducive to the design of the upper part of Wells anti-collision and ensure safe construction.

\subsection{Research on wellhead- target matching}

Durring the progressing of dense cluster wellbore trajectory scheme designing, the matching modes of wellhead--target have influence on inter-well anticollision prevention, total design footage, construction difficulty and so on. Therefore, the wellhead--target matching method is studied according to single row, double row (Figure2), and multi-row wellhead arrangement (Figure3). According to the principle of minimum displacement (Formula1), each group matched the target displacement (from the center point of the wellhead row) to the nearest wellhead in order from the largest to the smallest, and then matched the wellhead and the target from the inside to the outside, from near to far. By using the design software, the optimal distribution results of wellsite and target are quickly obtained. According to the principle of disjint of horizontal displacement, the preliminary single wellbore trajectory design is carried out, and the preliminary design scheme of each well position of the platform is made, which lays the foundation for the next step of fine trajectory adjustment and optimization.

$$
S=\sqrt{\left(X_{\mathrm{T}}-X_{\mathrm{W}}\right)^{2}+\left(Y_{\mathrm{T}}-Y_{\mathrm{W}}\right)^{2}}
$$

Annotation: S--Horizontal displacement between wellhead and target, $\mathrm{m}$

XT, Xw--the north-south coordinates of the target and the wellhead respectively, $m$

YT, Yw--the east-west coordinates of the target and the wellhead respectively, $\mathrm{m}$

This formula can be used to calculate the distance between two points with any known coordinates on the plane.

In general, the sequence of well cluster field drilling is that Wells with large horizontal displacement and shallow deviation point are priority to drill firstly, and then Wells with small displacement and deep deviation point drill latter. The purpose is to avoid the magnetic interference 
caused by the influence of adjacent casing on the drillrd well during directional deflection building, It is beneficial for directional deflection construction and borehole trajectory controlling for the wells drilled latter.

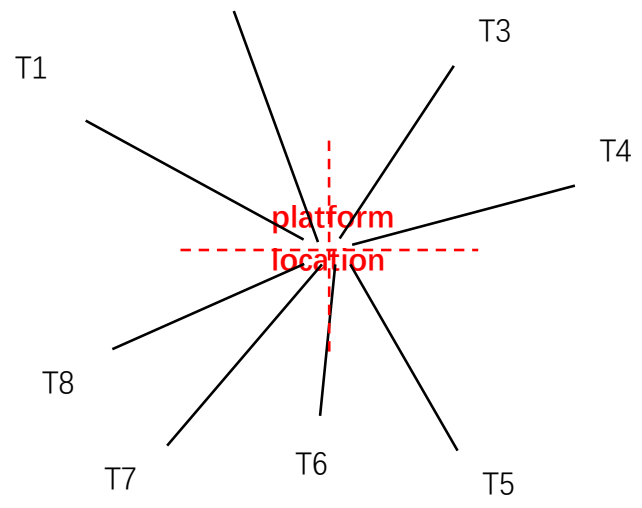

Figure 2: wellhead- target matching for Single row and double row wellhead

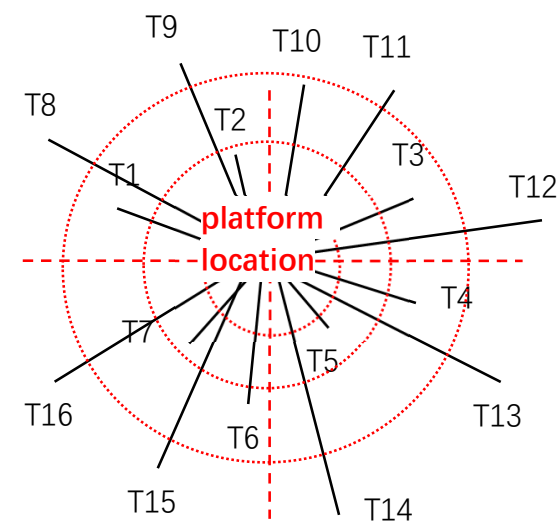

Figure 3: wellhead- target matching for multi-row wellhead

\section{3 study on the trajectory optimization of single well}

The optimal single wellbore trajectory have characters contains relatively suitable dogleg, minimum drilling footage, minimum torque, and frictional resistance while meeting the requirements of field tool capability. It also can reduce downhole accidents, shorten drilling cycle, reduce drilling costs, and facilitate the successful implementation of subsequent well completion, testing, workover, and injection-production operations.

\subsubsection{Section of profile type}

Considering the anti-collision and the construction difficulty, It is generally accepted that the profile In the design of dense cluster wellbore trajectory should be simplified, so two-dimensional trajectory design is recommended. Single-increment profile (straightincrement-stability) is preferred for Wells with small displacement in front of target and shallow oblique point. Double-increasing section (direct-increasing-stabilizing) or a five-section section (direct-increasing-stabilizing- lowering) can be considered to reduce the parallel length of the upper vertical section for wells with large displacement in front of the target. Take a horizontal well in Yangsanmu NO.1 platform for example (Table 1), which profile is designed as straight-increase-steadyincrease - steady section. Therefore the optimization of

Table 1 Comparison of parameters between single arc profile and double increase profile

\begin{tabular}{ccccc}
\hline $\begin{array}{c}\text { Profile } \\
\text { type }\end{array}$ & $\begin{array}{c}\text { Kickoff } \\
\text { point } \\
(\mathrm{m})\end{array}$ & $\begin{array}{c}\text { Build rate } \\
(\% / 30 \mathrm{~m})\end{array}$ & $\begin{array}{c}\text { Deviation } \\
\text { Angle }\left({ }^{\circ}\right)\end{array}$ & $\begin{array}{c}\text { Bottom } \\
\text { Depth } \\
(\mathrm{m})\end{array}$ \\
\hline $\begin{array}{c}\text { Single } \\
\text { gain }\end{array}$ & 785.25 & 2.670 & 90 & 1880 \\
$\begin{array}{c}\text { profile } \\
\text { Bibuld } \\
\text { profile }\end{array}$ & $\begin{array}{c}270 / 1199.5 \\
2\end{array}$ & $3.6 / 3.0^{\circ}$ & $20.08 / 90$ & 1776 \\
\hline
\end{tabular}

parallel anti - collision section in the minimum range by prefabrication is beneficial to safe drilling, and the stable slope design between the two increasing sections is conducive to correct the deviation of the trajectory during drilling. Compared with single arc profile its drilling footage is less, so it is recommended to choose the doubleincrease profile borehole track

\subsubsection{Parameter of profile selection}

Since the distance between dense cluster Wells' heads is generally within $6 \mathrm{~m}$, the upper vertical well section of each well is dangerous zone of anti-collision. Therefore, the desirable range of the kick off point must be determined firstly while the wellbore designing.

$$
\mathrm{H}=\mathrm{S} / \sin \alpha
$$

H--Possible wellbore collision depth, spacing, $\mathrm{m}$

$\mathrm{S}$--the wellhead spacing, the distance from the, $\mathrm{m}$ wellhead center minus the distance from the bit, $\mathrm{m}$

Combined with the characteristics of oilfield formation, the wellbore trajectory parameters are studied under the condition of multiple factors. It is researched that when the depth of the upper vertical section is within $1000 \mathrm{~m}$, the wellbore angle is $0.5^{\circ}$ (instrument accuracy error other factors error).Combined with the formation characteristics of Dagang oilfield, the wellbore trajectory parameters under multi-factor conditions were studied, The results show that the range of the kick off is preferably between 300 and 1100 meters, the build rate is between 1.5 and $3.6 \% 30 \mathrm{~m}$ (except for the highly-deviated Wells and horizontal Wells), and the wellbore Angle is controlled between 15 and $45^{\circ}$.

\subsubsection{Research on anti-collision technology}

Considerring that many Wells and small well spacing in cluser well, The problem of anti-collision is particularly prominent, which is the key of well cluster field drilling design. It is studied that trajectory parameters should be optimized first for anti-collision. Adjacent design kick off should be staggered $30-50 \mathrm{~m}$ above and below and arranged in "V" to reduce measuring instrument errors and ensure drilling safety. Taking a horizontal well platform for shale oil development as an example, there are 12 
Wells in a single well site, with $6 \mathrm{~m}$ wellhead spacing, $494 \mathrm{~m}$ maximum deviation and average well depth of more than $5017 \mathrm{~m}$, average horizontal section length of $1421 \mathrm{~m}$, and the horizontal section is arranged in a parallel manner considering the requirements of industrial fracturing operation in the later stage. Combined with trajectory optimization and formation characteristics, the anticollision design was carried out: After the track entered the second casing, the deviation Angle of $5 \sim 10^{\circ}$ was designed in advance to avoid collision between upper well section. The bottom hole uses the adjustment of kickoff point in the third casing which was staggered $30 \sim 80 \mathrm{~m}$ to reduce the risk collision; The build rates in special stratum is adiusted to ensure the quality of well. The trajectory is optimized to reduce the risk of collision, so that the anticollision coefficient between each well is greater than 1 .

\section{Application example analysis on the scene}

This method has been well applied in the optimization of wellbore trajectory of Yangsanmu No. 1 platform, Gangxi No.1 platform and Gangxi No. 2 Platform (Figure 4). Industrial drilling operation is implemented in Gangxi No. 2Platform in Gangxi 2 area, with 56 Wells

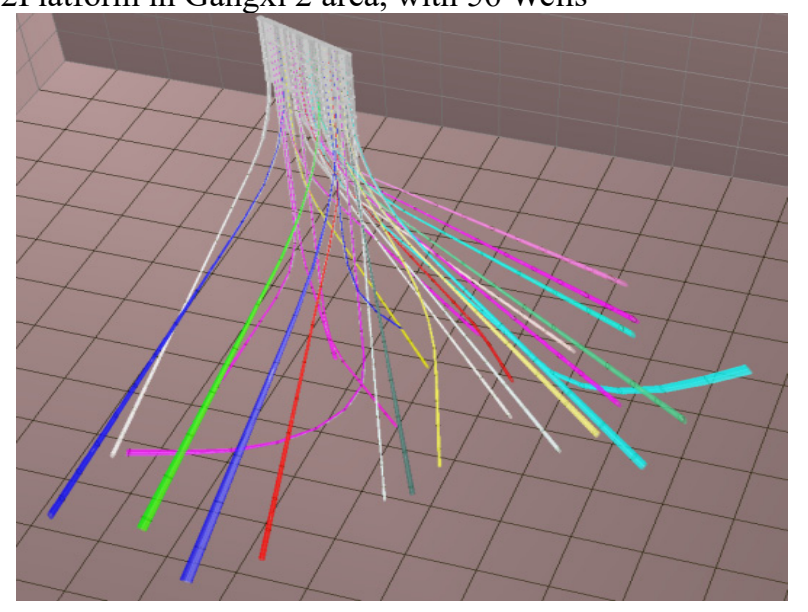

Figure 4 Three-dimensional projection of wellbore trajectory of f Cluster field in Gangxi NO.2 Platform

were deployed, and the slots were arranged in four groups in double row, with spacing of $8 \mathrm{~m}$ and $5 \mathrm{~m}$ respectively. The application of the cluster wellbore trajectory optimization method not only ensures the safety of the cluster well, but also saves the drilling cost. Through optimized design, 505 meters of drilling footage was saved and 1.8 million yuan of drilling flu id was reused. The drilling speed is increased obvious, the construction cycle is shortened by $32 \%$ and the mechanical drilling speed is increased by $45.13 \%$ compared with the single well in Gangxi 2area.

From 2018 to 2020 , a total of 217 cluster well sites have been built in Dagang Oilfield, with the proportion accounts to $68.2 \%$ of productive Wells. 24 cluster well sites with more than 6 Wells have been built. The Gangxi No.1 cluster well platform has become the demonstration well cluster site of CNPC. Through the application of dense cluster Wells, remarkable results have been achieved. The construction cost has been reduced by 302 million yuan accumulatively, and the construction and production cycle has been shortened by $12.3 \%$. Alleviated the situation of land difficulty of production capacity construction: land requisition for well site decreased by $8828 \mathrm{mu}$

\section{Conclusion and Suggestion}

(1) During the deployment process of dense cluster Wells, It is comprehensively analyzed considerring the feasibility of construction, engineering technology and construction cost in the later stage etc. And the number and type of platform Wells are integrated with geological engineering to ensure the implementation benefit optimization of dense cluster Wells.

(2) The wellhead--target matching is a key step in dense cluster well design, which followed the straight line method and the center of circle method: preliminary wellhead--target matching with disjoint horizontal displacement can be quickly realized from inside to outside, from inside to far and from the front, laying a good foundation for subsequent trajectory optimization. (3) It is considered that the design profile fo dense cluser wells strives for simplicity is uesd to the prevention of anticollision and the reduction of construction difficulty.it is recommended that two-dimensional profileis preferred. it is studied that the range of the kick off is preferably between 300 and 1100 meters, the building rate is between $1.5 \sim 3.6^{\circ} / 30 \mathrm{~m}$ (except for large slope Wells and horizontal Wells), and the hole Angle is controlled between 15 45 .

(4) The result of research showed that dense cluster well drilling improves the utilization rate of well site, and at the same time, it can save drilling cycle efficiently, with remarkable technical effect and outstanding economic benefits. This technology has great reference and promotion significance in similar oilfields.

\section{Introduction of the first author}

Wang Guona, Graduated from China University of Petroleum (East China) with a master's degree in 2011; Engineer, mainly engaged in drilling engineering design and related research. Mailing address: Dagang Oilfield Petroleum Engineering Research Institute, Zip code: 300280. E-mail: wanggna@petrochina.com.cn.

\section{References:}

1. Yan Tie, Xu ting et al. M.M. Oil drilling technology, 13 16 (2013);

2. Ge Yunhua, Yan Mmin et al.Petroleum exploration and development, 32(5): 94 100(2006);

3. Dong deren, Zhang NaiTong et al, Petroleum Drilling and Production Technology, 31 (2009.)

4. Liu YongWang, Guan ZhiChuan etal, Petroleum Drilling and Production Technology, 33 (6): 1517(2011)

5. Zhao Jingshan, Drilling Technology of horizontal 
Wells in shengli Oil Drilling Technology, (5): 72$7(2003)$

6. LI Kuizhou, Chen Shumin. Petroleum Geology and Oilfield Development in Daqing, 38(6):7-12(2018);

7. Hu hongzhi Hou Yiet al. Oil Drilling\& Production Technogy,41(4):448-454(2019) 